\title{
The Clinical Significance of Alpha-Fetoprotein mRNAs in Patients with Hepatocellular Carcinoma
}

\author{
Shogo Kobayashi Akira Tomokuni Hidenori Takahashi Hirofumi Akita \\ Keijiro Sugimura Norikatsu Miyoshi Jeong Ho Moon Masayoshi Yasui \\ Takeshi Omori Masayuki Ohue Yoshiyuki Fujiwara Masahiko Yano \\ Masato Sakon \\ Department of Surgery, Osaka Medical Center for Cancer and Cardiovascular Diseases, \\ Osaka, Japan
}

\author{
Keywords \\ Alpha-fetoprotein $\cdot$ Hepatectomy $\cdot$ Hepatocellular carcinoma
}

\begin{abstract}
Background/Aims: Alpha-fetoprotein (AFP) mRNA-expressing cells are candidates for circulating tumor cells in hepatocellular carcinoma. We analyzed portal vein blood, peripheral blood, and peritoneal lavage samples to detect the presence of AFP mRNA-expressing cells, and explored their relationship with metastasis. Methods: We measured the AFP mRNA expression in 112 sets of portal vein and peripheral blood samples and 61 peritoneal lavage samples that had been obtained during surgery. We estimated the change in the positive ratio of patients with AFP mRNA, the associated background factors, and the rate of recurrence. Results: The change in AFP mRNA positivity in the peripheral blood specimens was remarkable, while that in the portal vein blood and peritoneal lavage samples was similar during hepatectomy. Tumor location was the only factor associated with AFP mRNA positivity. The rate of recurrence was higher in the patients who were positive for AFP mRNA than in those who were negative 9-24 months after hepatectomy. During this limited period, the recurrence rate in the AFP mRNA-positive cases was significantly higher than that in the AFP mRNA-negative cases $(p=0.0472)$. Postoperative AFP mRNA positivity was not related to very early recurrence (0-9 months) or multicentric liver carcinogenesis ( $>24$ months). Conclusion: AFP mRNA positivity in the peripheral blood was elevated after hepatectomy, and the elevation depended on the tumor location. AFP mRNA positivity might contribute to recurrence-free survival 9-24 months after hepatectomy.




\section{Introduction}

The detection and analysis of circulating tumor cells (CTCs) is expected to be helpful for both predicting recurrence after surgery and for selecting an appropriate surgical strategy. Thus, as a tool for detecting CTCs, we investigated the presence of alpha-fetoprotein (AFP) mRNA-expressing cells in patients with hepatocellular carcinoma (HCC). To date, previous studies have investigated at most $80-90$ patients, and have shown the possible predictive value of the detection of AFP mRNA in peripheral blood samples for recurrence; however, the impact with regard to recurrence remains controversial [1-5]. Some authors have reported that AFP mRNA predicts extra- or intrahepatic metastasis, whereas others have reported contradictory findings; for example, they showed that the elevation of AFP mRNA during surgery occurred due to diseases other than HCC [6, 7].

Thus, further investigations are needed to clarify the roles of AFP mRNA-expressing cells. First, it is necessary to investigate the surgery-related changes in AFP mRNA before and after hepatectomy. AFP mRNA may potentially be detected in blood samples from the hepatic vein (systemic circulation) or the hepatic portal system, or from peritoneal lavage samples. Second, it is necessary to consider that - in some cases - HCC recurrence may not be related to CTCs. Recurrence in the late phase may be related to multicentric liver carcinogenesis due to viral hepatitis, alcoholic and non-alcoholic steatohepatitis, and liver cirrhosis [8]; only early-phase recurrence would be related to intrahepatic metastasis, which may be induced by CTCs. Additionally, we should note the potential for the existence of metastasis that cannot be visualized using the current imaging technology at the time of surgery; such metastasis could lead to very early recurrence.

In the present study, we investigated the presence of AFP mRNA in peripheral blood, portal vein blood, and peritoneal lavage samples from more than 100 HCC patients, and explored the surgery-related changes in AFP mRNA positivity and the relationship between such changes and recurrence after surgery.

\section{Patients and Methods}

\section{Patients}

A total of 273 patients with HCC underwent hepatectomy at our institution between 2002 and 2007. The levels of AFP mRNA in both the portal vein and peripheral blood were measured simultaneously in 112 of these patients. These patients were included in the subsequent analysis (note: the levels of AFP mRNA were measured in the portal vein blood and peripheral blood of 213 patients and 120 patients, respectively). The AFP mRNA levels were measured in the peritoneal lavage samples of 61 patients (55\%). Patients with recurrent HCC more than 2 years after surgery (8\%) were included in the study. This study was approved by the institutional review board at Osaka Medical Center for Cancer and Cardiovascular Diseases, and written informed consent was obtained from all of the subjects.

The stage of HCC was classified according to the General Rules for the Clinical and Pathological Study of Primary Liver Cancer (5th edition) issued by the Liver Cancer Study Group of Japan.

Quantitative PCR to Detect AFP mRNA in Portal Vein Blood, Peripheral Blood, and Peritoneal Lavage Samples

Portal vein blood and peripheral blood $(8 \mathrm{~mL})$ samples and peritoneal lavage samples were obtained before and immediately after hepatectomy. For the measurement of the AFP mRNA levels in peritoneal lavage samples, warm saline $(100 \mathrm{~mL})$ was introduced into the liver bed immediately after laparotomy, and $50 \mathrm{~mL}$ of saline was aspirated. Additionally, peripheral blood was obtained and blood was collected from the portal vein (at the umbilical portion in patients with right liver tumors or at the confluence of the anterior and posterior portal veins in patients with left liver tumors) before liver mobilization. Peritoneal lavage, portal vein blood, and peripheral blood samples were also obtained immediately after hepatectomy, following the confirmation of primary hemostasis at the cut surface of the liver. 


\section{Tumors}

Table 1. Patient characteristics
112

$68(66.4 \pm 8.9)$

$89(79 \%)$

$23(21 \%)$

$32(29 \%)$

$71(63 \%)$

$84(75 \%)$

$28(25 \%)$

$108(96 \%)$

$4(4 \%)$

$52(46 \%)$

$56(50 \%)$

$28(25 \%)$

$103(92 \%)$

$33(42.7 \pm 33.1)$

87 (78\%)

$4(4 \%)^{\mathrm{a}}$

$39(35 \%)$

$5(4 \%)$

$68(61 \%)$

73 (65\%)/39 (35\%)

$227(245.5 \pm 101.0)$

$1,000(1,225 \pm 1,043)$

$200(303 \pm 411)$

$21(19 \%)$

$56(50 \%)^{b}$

$48(43 \%)$

$82(73 \%)$

$22(20 \%)$

$8(7 \%)$

$7(6 \%)$

Values are given as $n(\%)$ or median (mean \pm standard deviation). AFP, alpha-fetoprotein; CPT, Child-Pugh-Turcotte; DCP, des-gammacarboxy prothrombin (PIVKA-II, a protein induced by the absence of vitamin $\mathrm{K}$ or an antagonist); HBV, hepatitis B virus infection; $\mathrm{HCV}$, hepatitis $\mathrm{C}$ virus infection; SD, standard deviation; TACE, transcatheter arterial chemoembolization. ${ }^{\mathrm{a}}$ Two portal vein, 3 hepatic vein. ${ }^{\mathrm{b}}$ Fifty-six portal vein, 3 hepatic vein, 2 hepatic artery.

The method used to detect AFP mRNA has been described previously [9]. Briefly, blood samples were collected in a VACUTAINER CPT ${ }^{\text {TM }}$ cell preparation tube with sodium citrate (Becton Dickinson, Franklin Lakes, NJ, USA) and centrifuged at $17,000 \mathrm{~g}$ for $20 \mathrm{~min}$. The separated mononuclear cells were placed into a 15 -mL centrifugation tube, suspended with $10 \mathrm{ml}$ of phosphate-buffered saline, and centrifuged at 2,000 rpm for $10 \mathrm{~min}$. After washing with phosphate-buffered saline, the cells were suspended with TRIzol Reagent 
Kobayashi et al.: The Clinical Significance of Alpha-Fetoprotein mRNAs in Patients with Hepatocellular Carcinoma

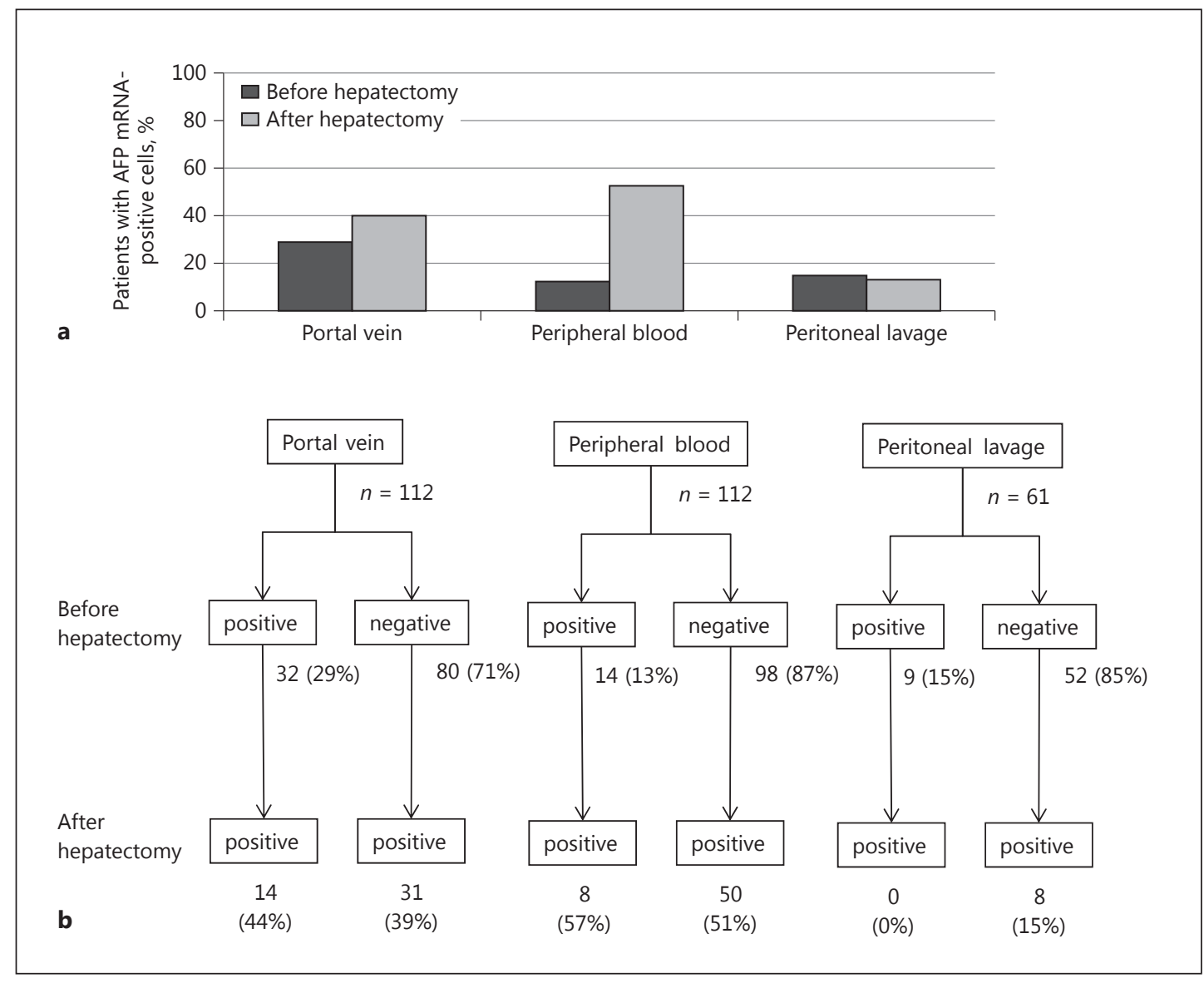

Fig. 1. Perioperative changes in the positive ratio of patients with alpha-fetoprotein (AFP) mRNA in portal vein blood, peripheral blood, and peritoneal lavage samples. a Percentages of patients in whom AFP mRNA was detected before and after hepatectomy. $\mathbf{b}$ Change in the positive ratio of patients with AFP mRNA before and after hepatectomy. The numbers indicate the number of patients (with percentage in parentheses).

(Molecular Research Center, Cincinnati, OH, USA) and stored at $-80^{\circ} \mathrm{C}$ until RNA isolation. The following primers were used for the PCR: forward: 5'-TCA GTG AGG ACA AAC TAT TGG-3' and reverse: $5^{\prime}$-CTC TTC AGC AAA GCA GAC TTC- $3^{\prime}$. HuH7 cells were used as a positive control. AFP mRNA was quantified using the LightCycler $^{\mathrm{TM}}$ software program (Roche Diagnostics, Mannheim, Germany) according to the manufacturer's protocol. The detection of AFP mRNA at any level was considered to be a positive result.

\section{The Follow-Up Evaluation}

Blood tests (including measurements of AFP and des-gamma-carboxy prothrombin [PIVKA-II, a protein induced by the absence of vitamin $\mathrm{K}$ or an antagonist] levels $[10,11]$ ) and/or imaging tests (enhanced computed tomography or magnetic resonance imaging) were planned every 3 months (at a minimum) after surgery. Additional blood tests and imaging examinations were performed to confirm recurrence if clinically suspected. The rates of overall survival (OS) and recurrence-free survival (RFS) were calculated from the time of surgery.

\section{Statistical Analysis}

The rates of OS and cumulative recurrence were calculated according to the Kaplan-Meier method. Differences between groups were evaluated using the log-rank test. Hazard ratios were calculated using Cox's proportional hazards model, and the recurrence rate every 3 months was calculated based on the number of recurrent and surviving cases at that time. A landmark analysis was used to investigate the cumu- 
lative recurrence rate during the target period. Differences between groups were evaluated using the Student $t$ test and the $\chi^{2}$ test. $p$ values $<0.05$ were considered to indicate statistical significance. All of the statistical analyses were performed using the StatView J-5.0 software program (SAS, Cary, NC, USA).

\section{Results}

\section{Patient Characteristics}

Patient characteristics are summarized in Table 1. The mean tumor size was $42.7 \mathrm{~mm}$, $78 \%$ of the lesions were single HCC tumors, $73 \%$ of the lesions were stage I or II tumors, and vascular invasion was only noted in $3.6 \%$ of the patients in this series. Preoperative transcatheter arterial chemoembolization (TACE) was performed in $25 \%$ of patients. All patients underwent open hepatectomy, with $65 \%$ of the patients undergoing anatomical resection. R0 resection was achieved in $94 \%$ of the patients. The RFS rates 1,3 , and 5 years after hepatectomy were $72.1,35.2$, and $22.8 \%$, respectively, while the OS rates were $93.6,77.3$, and $68.2 \%$, respectively. The median follow-up period was 5.8 years.

\section{Detection of AFP mRNA in Portal Vein Blood, Peripheral Blood, and Peritoneal Lavage}

Samples before and after Hepatectomy

Before hepatectomy, the positive ratios of patients with AFP mRNA in their portal vein blood, peripheral blood, and peritoneal lavage samples were 29,13 , and $15 \%$, respectively. In contrast, after hepatectomy, the positive ratios of patients with AFP mRNA in their portal vein blood, peripheral blood, and peritoneal lavage samples were 40, 53, and 13\%, respectively (Fig. 1a). The rate was only elevated in the peripheral blood after hepatectomy $(p<$ 0.0001 ). With regard to the change in AFP mRNA positivity, the rate of AFP mRNA positivity after hepatectomy did not differ according to the presence or absence of AFP mRNA before hepatectomy (Fig. 1b). These data indicate that hepatectomy increased the positive ratio of patients with AFP mRNA in their peripheral blood samples. We therefore investigated the features associated with AFP mRNA positivity after hepatectomy, to explore the factors that possibly affected AFP mRNA positivity; the findings are summarized in Table 2. Most of the perioperative factors (tumor factors, background liver status, and hepatectomy) did not differ between the AFP mRNA-positive and the AFP mRNA-negative group; however, tumor location was associated with AFP mRNA positivity. Specifically, the major tumor locations associated with postoperative AFP mRNA positivity were segments 7 and 8 , whereas the minor locations were segments 2 and 3. The rate at which AFP mRNA was detected in preoperative peripheral blood samples was similar among the different tumor locations $15 \%$ in segments 7 or $8,10 \%$ in segment 2 or 3 , and $12 \%$ in other locations). These data indicate that the rate of AFP mRNA-positive peripheral blood samples increased after hepatectomy, and that the increase depended on tumor location.

\section{Relationship between Recurrence and Detection of AFP mRNA in the Postoperative Peripheral Blood Samples}

We investigated the incidence of recurrence in association with the detection of AFP mRNA in the postoperative peripheral blood samples as a factor that was potentially affected by AFP mRNA. The recurrence rates after hepatectomy are shown in Figure 2. The cumulative recurrence rate did not differ according to presence or absence of AFP mRNA ( $p=0.42$, Fig. 2a); however, the recurrence rate in the patients whose postoperative samples were positive for AFP mRNA was $5-10 \%$ higher than that observed in the patients whose postoperative samples were negative for AFP mRNA during the initial 1-3 years after hepatectomy - which is likely to be associated with residual intrahepatic metastasis [8]. The rates of 


\section{Tumors}

DOI: $10.1159 / 000455955$

Table 2. Patient characteristics in the group positive for postoperative AFP mRNA in the peripheral blood

\begin{tabular}{|c|c|c|c|}
\hline \multirow[t]{2}{*}{ Variables } & \multicolumn{2}{|c|}{ Postoperative AFP mRNA in peripheral blood } & \multirow[t]{2}{*}{$p$} \\
\hline & positive $(n=58)$ & negative $(n=54)$ & \\
\hline Age, years & $68.5(66.8 \pm 9.2)$ & $67.5(65.9 \pm 8.7)$ & 0.60 \\
\hline \multicolumn{4}{|l|}{ Sex } \\
\hline Male & $47(81 \%)$ & $42(78 \%)$ & 0.67 \\
\hline \multicolumn{4}{|l|}{ Etiology } \\
\hline HBV & $19(33 \%)$ & $13(24 \%)$ & 0.31 \\
\hline HCV & $38(66 \%)$ & $33(61 \%)$ & 0.63 \\
\hline \multicolumn{4}{|l|}{ Liver damage } \\
\hline A & $45(78 \%)$ & $39(72 \%)$ & \multirow[t]{2}{*}{0.51} \\
\hline $\mathrm{B}$ & $13(22 \%)$ & $15(28 \%)$ & \\
\hline \multicolumn{4}{|l|}{ CPT score } \\
\hline A & $56(97 \%)$ & $52(96 \%)$ & \multirow[t]{2}{*}{0.93} \\
\hline $\mathrm{B}$ & $2(3 \%)$ & $2(4 \%)$ & \\
\hline \multicolumn{4}{|l|}{ AFP } \\
\hline$>20 \mathrm{ng} / \mathrm{mL}$ & $29(50 \%)$ & $23(43 \%)$ & 0.43 \\
\hline \multicolumn{4}{|l|}{ DCP } \\
\hline$>40 \mathrm{mAU} / \mathrm{mL}$ & $37(64 \%)$ & $29(54 \%)$ & 0.28 \\
\hline TACE & $12(21 \%)$ & $16(30 \%)$ & 0.28 \\
\hline \multicolumn{4}{|l|}{ Primary/recurrence } \\
\hline Primary & $55(95 \%)$ & $48(89 \%)$ & 0.25 \\
\hline Tumor size, $\mathrm{cm}$ & $31(40 \pm 34)$ & $34(46 \pm 31)$ & 0.39 \\
\hline \multicolumn{4}{|l|}{ Number of tumors } \\
\hline Single & $46(79 \%)$ & $41(76 \%)$ & 0.67 \\
\hline Macroscopic vascular invasion & $3(5 \%)$ & $1(2 \%)$ & 0.34 \\
\hline \multicolumn{4}{|l|}{ Type of surgery } \\
\hline Partial hepatectomy & $18(31 \%)$ & $20(37 \%)$ & \multirow[t]{3}{*}{0.65} \\
\hline Subsegmentectomy & $4(7 \%)$ & $2(4 \%)$ & \\
\hline Sectionectomy or more & $36(62 \%)$ & $32(59 \%)$ & \\
\hline Anatomical resection & $39(67 \%)$ & $34(63 \%)$ & 0.63 \\
\hline Operative time, min & $247(258 \pm 99)$ & $205(230 \pm 101)$ & 0.16 \\
\hline Blood loss, g & $1,027(1,329 \pm 1,193)$ & $920(1,106 \pm 838)$ & 0.27 \\
\hline Liver resection weight, $\mathrm{g}$ & $217(321 \pm 482)$ & $185(282 \pm 316)$ & 0.62 \\
\hline \multicolumn{4}{|l|}{ Histology } \\
\hline Poorly differentiated & $12(21 \%)$ & $13(24 \%)$ & 0.67 \\
\hline Microscopic vascular invasion & $30(50 \%)$ & $26(48 \%)$ & 0.71 \\
\hline \multicolumn{4}{|l|}{ Liver pathology } \\
\hline $\mathrm{F} 3 / 4$ & $22(38 \%)$ & $26(48 \%)$ & 0.27 \\
\hline \multicolumn{4}{|l|}{ Stage } \\
\hline $\mathrm{I} / \mathrm{II}$ & $43(74 \%)$ & $39(72 \%)$ & \multirow[t]{3}{*}{0.97} \\
\hline III & $11(20 \%)$ & $11(20 \%)$ & \\
\hline IVa & $4(7 \%)$ & $4(7 \%)$ & \\
\hline \multicolumn{4}{|l|}{ Residual tumor } \\
\hline $\mathrm{R} 1$ & $3(5 \%)$ & $4(7 \%)$ & 0.63 \\
\hline \multicolumn{4}{|l|}{ Tumor location } \\
\hline Segment $2 / 3$ & $2(3 \%)$ & $8(15 \%)$ & 0.0350 \\
\hline Segment 7/8 & $22(38 \%)$ & $12(22 \%)$ & 0.0708 \\
\hline
\end{tabular}

Values are given as $n(\%)$ or median (mean \pm standard deviation). Bold text indicates $p$ values $<0.1$. AFP, alpha-fetoprotein; CPT, Child-Pugh-Turcotte; DCP, des-gamma-carboxy prothrombin (PIVKA-II, a protein induced by the absence of vitamin $\mathrm{K}$ or an antagonist); TACE, transcatheter arterial chemoembolization; HBV, hepatitis B virus infection; HCV, hepatitis C virus infection. 


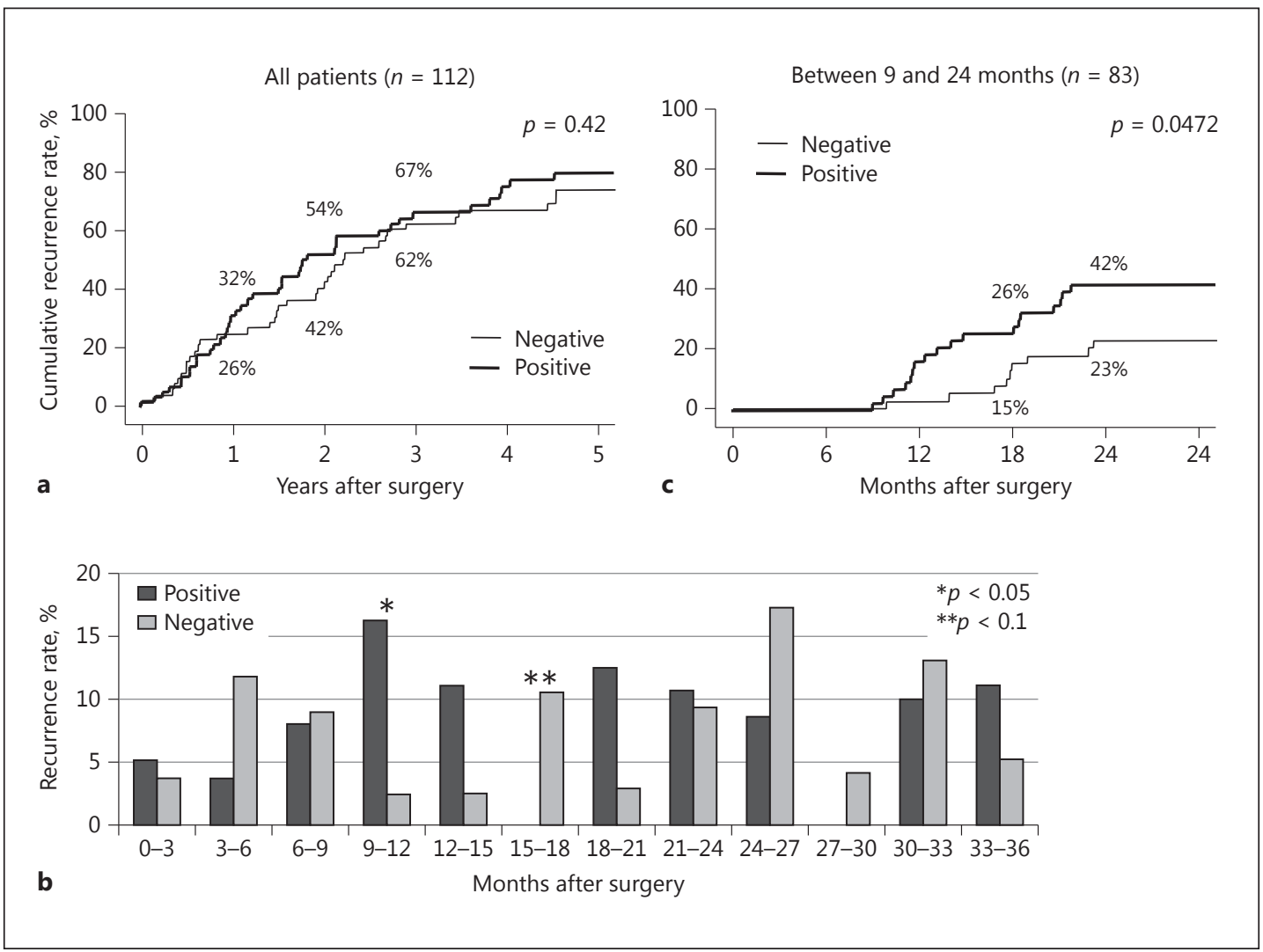

Fig. 2. Recurrence rate after hepatectomy according to presence or absence of alpha-fetoprotein (AFP) mRNA in the postoperative peripheral blood. "Positive" indicates that AFP mRNA was detected, "negative" that AFP mRNA was not detected. a Cumulative recurrence rate after hepatectomy in the cases with or without AFP mRNA $(n=112)$. b Recurrence rates every 3 months after hepatectomy. c Cumulative recurrence rate 9-24 months after hepatectomy.

recurrence in the groups of patients who were positive and negative for AFP mRNA every 3 months during this period are shown in Figure 2b. The recurrence rate in the patients who were positive for AFP mRNA was higher than that in the patients who were negative for AFP mRNA in most of the periods from 9 to 24 months after surgery (the higher recurrence rate among the patients who were negative for AFP mRNA at 15-18 months might have been caused by micro-portal vein invasion). We noted that multicentric carcinogenesis was a major cause of recurrence at $>24$ months [8]. Based on this information, we investigated the cumulative recurrence rate 9-24 months after surgery. Consequently, a landmark analysis revealed that the cumulative recurrence rate in the patients who were positive for AFP mRNA during this period was significantly higher in comparison to the patients who were negative for AFP mRNA ( $p=0.0472$, Fig. $2 c$ ). These data indicate the possibility that the detection of AFP mRNA in the peripheral blood was associated with the development of recurrence 9-24 months after hepatectomy.

In order to compare the patterns of recurrence after hepatectomy, we investigated the patient characteristics, including the positive ratio of patients with AFP mRNA, and the hazard ratios in several postoperative periods (Table 3). We divided the postoperative period into $<9$ months, 9-24 months, and $>24$ months, and determined the association between AFP mRNA positivity and recurrence by a landmark analysis. The unfavorable factors for RFS 
Gastro

Intestinal

Tumors
Gastrointest Tumors 2016:3:141-152

DOI: 10.1159/000455955

Kobayashi et al.: The Clinical Significance of Alpha-Fetoprotein mRNAs in Patients with

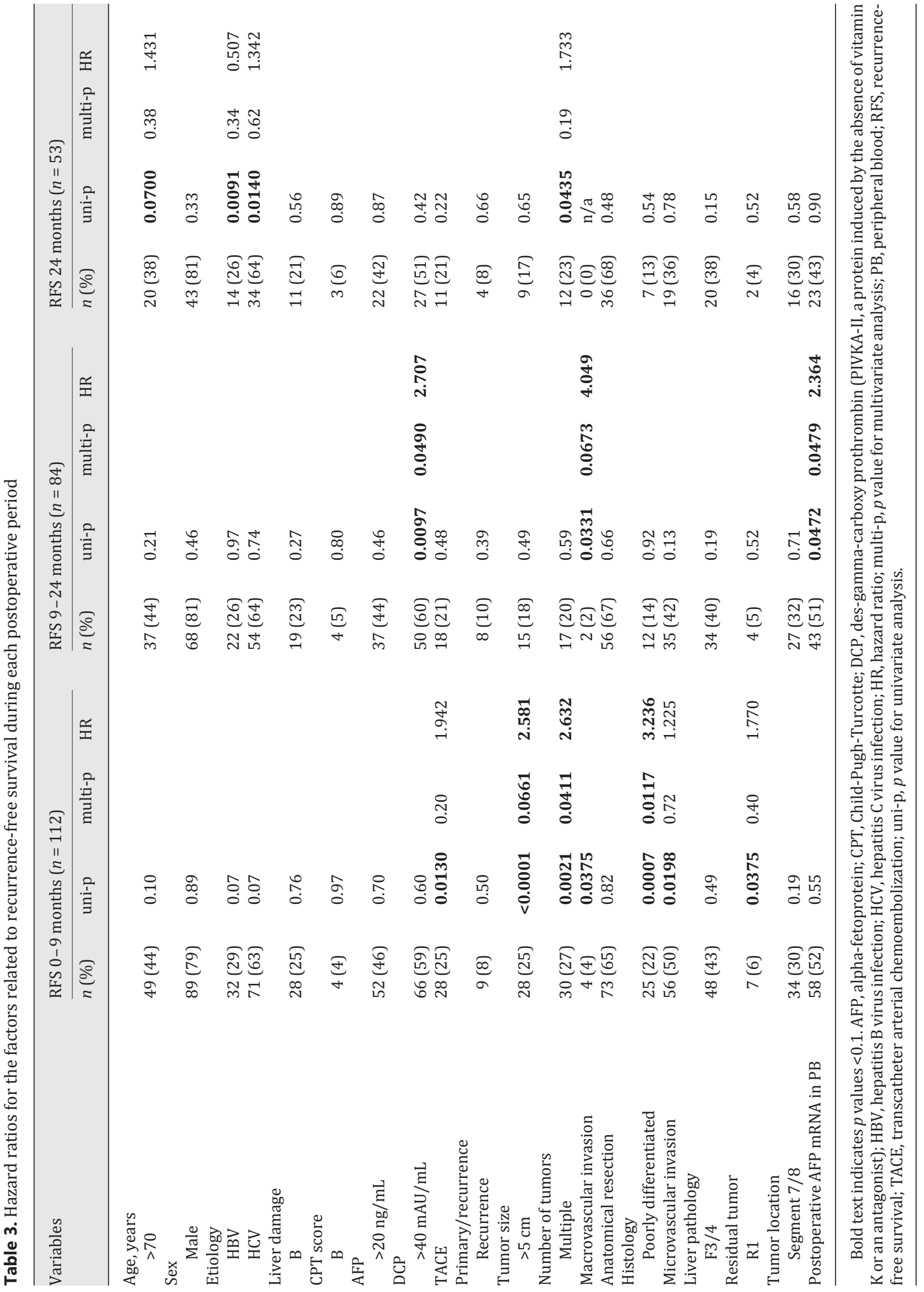


differed among the postoperative periods. A univariate analysis revealed that at a postoperative period of $<9$ months, preoperative TACE, residual tumors, and regular tumor factors (e.g., tumor size, tumor number, macro-/microvascular invasion, and histological grade) were associated with an unfavorable prognosis. A multivariate analysis revealed that number of tumors and histology were independent prognostic factors, while tumor size tended to be associated with recurrence. Conversely, a univariate analysis revealed that des-gammacarboxy prothrombin elevation, macrovascular invasion, and AFP mRNA positivity at 9-24 months were associated with an unfavorable prognosis. With the exception of macrovascular invasion, which showed a trend toward an association with recurrence, all of these factors were found to be independent prognostic factors in a multivariate analysis. At $>24$ months, a time point that was thought to be associated with multicentric liver carcinogenesis [8], age, hepatitis $\mathrm{C}$ status, and tumor number were identified as being associated with an unfavorable prognosis, but only according to univariate analysis.

\section{Discussion}

The present analysis showed that surgery-related changes in the positive ratio of patients with AFP mRNA only occurred in the peripheral blood and that they depended on tumor location. Furthermore, this finding was associated with recurrence 9-24 months after hepatectomy.

First, we need to consider what the presence of AFP mRNA-expressing cells represents. In liver transplant recipients with HCC, preoperative AFP mRNA positivity is a risk factor for recurrence [12], while the detection of AFP mRNA before surgery in patients undergoing TACE is associated with worse survival [13]. In addition to these risks associated with preoperative AFP mRNA, many authors have demonstrated that the rate of AFP mRNA positivity is increased after hepatectomy, as was shown in our data [1-3, 6, 14-16]. Consequently, AFP mRNA-expressing cells are believed to be associated with the risk of recurrence or survival and surgical treatment. However, AFP mRNA-expressing cells are not equivalent to CTCs rather, they include CTCs - as some authors have reported the detection of AFP mRNAexpressing cells after liver surgery in patients without HCC [6, 7]. Although it will be necessary to more precisely identify the CTCs in HCC in order to clarify the role of these cells, the detection of AFP mRNA should therefore be analyzed to predict survival.

It remains possible that AFP mRNA is associated with recurrence or survival and that the positive ratio of patients with AFP mRNA increases as a result of liver surgery. Although no changes were noted in the rate of portal vein or peritoneal lavage samples that were positive for AFP mRNA, such changes were detected in the peripheral blood. There is little information about AFP mRNA outside of the peripheral blood (e.g., bone marrow [1,14]), and it is difficult to confirm our data. The increased positive ratio of AFP mRNA in the portal vein was limited in approximately $10 \%$ of cases; however, portal vein invasion would be a risk factor for recurrence after surgery [17]. In the peritoneal lavage samples, the rate of patients who were positive for AFP mRNA was low, and there was no increase in the rate of detection after liver surgery. This observation is also expected to be caused by the low incidence of hepatic capsule invasion, which was $0 \%$ in our series (data not shown). In contrast, major changes in AFP mRNA positivity were noted in the peripheral blood, and these changes depended on the circulation of the cells based on varied tumor hemodynamics according to the surgical manipulation [18].

The recurrence of HCC involves residual intrahepatic metastasis and multicentric liver carcinogenesis [8]. The former consists of an early recurrent phase, which occurs within 2 years, while the latter consists of a late recurrent phase, which occurs after 4 years [8]. Our 
data showed that AFP mRNA was detected at a particularly high rate in the early recurrent phase, especially 9-24 months after surgery. Based on the recurrence-related factors, which were observed within 9 months after surgery, it is possible that this very early phase is associated with metastasis at the time of surgery, which cannot be visualized using current imaging technology. In contrast, the recurrence-related factors that were noted more than 2 years after surgery, in the late recurrence phase, were thought to have been due to the presence of multicentric liver carcinogenesis - despite our data only showing differences in the univariate analysis [8]. Our data suggest that the presence of AFP mRNA was only associated with recurrence 9-24 months after surgery and that it takes time to visualize CTCs. The RFS curves in the previous reports also showed the disadvantage of AFP mRNA positivity 9-24 months after surgery $[1-3,16,19]$, whereas other reports showed no statistically significant findings $[1,2,16]$. In these reports, the authors used the log-rank test, which is effective for the statistical analysis of later survival. In an analysis of several periods after surgery which was based on the presented survival curve - the RFS in the patients who were positive for AFP mRNA and those who were negative for AFP mRNA was similar 3-9 months after surgery. In contrast, the later RFS (12-36 months) in the patients who were positive for AFP mRNA was 10-30\% worse than that observed in the patients who were negative for AFP mRNA $[1-3,16,19]$. It is necessary to investigate recurrence according to the period after treatment based on the pathogenesis of metastasis.

It is possible that surgical manipulation leads to the presence of AFP mRNA in the peripheral blood; thus, it may be advantageous to perform laparoscopic hepatectomy. We therefore reviewed studies that showed the long-term outcomes of laparoscopic hepatectomy versus open hepatectomy: 2 authors showed that laparoscopic hepatectomy offered an advantage in terms of RFS [20,21], 1 author showed slightly higher RFS at 1-2 years [22], while the others showed no advantage in terms of RFS [23-25]. Unfortunately, there was little information regarding the detailed tumor location or the small number of tumors in segments 7 and 8, which were found to be associated with a high rate of AFP mRNA positivity after open hepatectomy in our study. We started a further study (UMIN-CTR: UMIN000016341) to confirm the relationship between AFP mRNA positivity and short-term recurrence based on surgical procedure, especially laparoscopic hepatectomy.

In conclusion, the rate of AFP mRNA positivity was elevated in the peripheral blood after surgery in this study; this elevation depended on tumor location, and it might have contributed to RFS 9-24 months after surgery. On the other hand, the postoperative AFP mRNA positivity of peripheral blood was not related to very early recurrence (0-9 months) or multicentric liver carcinogenesis ( $>24$ months). Thus, it is necessary to develop a surgical strategy that reduces the rate of patients whose peripheral blood is positive for AFP mRNA after surgery.

\section{Acknowledgment}

The manuscript was proofread by a professional editor and native English speaker at Japan Medical Communication (http://www.japan-mc.co.jp).

\section{Disclosure Statement}

The authors declare no conflicts of interest in association with the present study. 


\section{References}

1 Kamiyama T, Takahashi M, Nakagawa T, Nakanishi K, Kamachi H, Suzuki T, Shimamura T, Taniguchi M, Ozaki M, Matsushita M, Furukawa H, Todo S: AFP mRNA detected in bone marrow by real-time quantitative RT-PCR analysis predicts survival and recurrence after curative hepatectomy for hepatocellular carcinoma. Ann Surg 2006;244:451-463.

2 Marubashi S, Nagano H, Wada H, Kobayashi S, Eguchi H, Takeda Y, Tanemura M, Umeshita K, Doki Y, Mori M: Clinical significance of alpha-fetoprotein mRNA in peripheral blood in liver resection for hepatocellular carcinoma. Ann Surg Oncol 2011;18:2200-2209.

3 Ijichi M, Takayama T, Matsumura M, Shiratori Y, Omata M, Makuuchi M: Alpha-fetoprotein mRNA in the circulation as a predictor of postsurgical recurrence of hepatocellular carcinoma: a prospective study. Hepatology 2002;35:853-860.

4 Gross-Goupil M, Saffroy R, Azoulay D, Precetti S, Emile JF, Delvart V, Tindilière F, Laurent A, Bellin MF, Bismuth H, Debuire B, Lemoine A: Real-time quantification of AFP mRNA to assess hematogenous dissemination after transarterial chemoembolization of hepatocellular carcinoma. Ann Surg 2003;238:241-248.

5 Minata M, Nishida N, Komeda T, Azechi H, Katsuma H, Nishimura T, Kuno M, Ito T, Yamamoto Y, Ikai I, Yamaoka Y, Fukuda Y, Nakao K: Postoperative detection of alpha-fetoprotein mRNA in blood as a predictor for metastatic recurrence of hepatocellular carcinoma. J Gastroenterol Hepatol 2001;16:445-451.

6 Kienle P, Weitz J, Klaes R, Koch M, Benner A, Lehnert T, Herfarth C, von Knebel Doeberitz M: Detection of isolated disseminated tumor cells in bone marrow and blood samples of patients with hepatocellular carcinoma. Arch Surg 2000;135:213-218.

7 Aselmann H, Wolfes H, Rohde F, Frerker M, Deiwick A, Jäger MD, Klempnauer J, Schlitt HJ: Quantification of alpha 1-fetoprotein mRNA in peripheral blood and bone marrow: a tool for perioperative evaluation of patients with hepatocellular carcinoma. Langenbecks Arch Surg 2001;386:118-123.

8 Sakon M, Umeshita K, Nagano H, Eguchi H, Kishimoto S, Miyamoto A, Ohshima S, Dono K, Nakamori S, Gotoh M, Monden M: Clinical significance of hepatic resection in hepatocellular carcinoma: analysis by diseasefree survival curves. Arch Surg 2000;135:1456-1459.

9 Miyamoto A, Nagano H, Sakon M, Fujiwara Y, Sugita Y, Eguchi H, Kondo M, Arai I, Morimoto O, Dono K, Umeshita K, Nakamori S, Monden M: Clinical application of quantitative analysis for detection of hematogenous spread of hepatocellular carcinoma by real-time PCR. Int J Oncol 2001;18:527-532.

10 Sakon M, Monden M, Gotoh M, Kobayashi K, Kanai T, Umeshita K, Endoh W, Mori T: The effects of vitamin K on the generation of des-gamma-carboxy prothrombin (PIVKA-II) in patients with hepatocellular carcinoma. Am J Gastroenterol 1991;86:339-345.

11 Sakon M, Monden M, Gotoh M, Kanai T, Umeshita K, Nakano Y, Mori T, Sakurai M, Wakasa K: Relationship between pathologic prognostic factors and abnormal levels of des-gamma-carboxy prothrombin and alphafetoprotein in hepatocellular carcinoma. Am J Surg 1992;163:251-256.

12 Marubashi S, Dono K, Nagano H, Sugita Y, Asaoka T, Hama N, Miyamoto A, Takeda Y, Umeshita K, Monden M: Detection of AFP mRNA-expressing cells in the peripheral blood for prediction of HCC recurrence after living donor liver transplantation. Transpl Int 2007;20:576-582.

13 Murakami M, Nagano H, Kobayashi S, Wada H, Nakamura M, Marubashi S, Eguchi H, Takeda Y, Tanemura M, Umeshita K, Doki Y, Mori M: Effects of pre-operative transcatheter arterial chemoembolization for resectable hepatocellular carcinoma: implication of circulating cancer cells by detection of $\alpha$-fetoprotein mRNA. Exp Ther Med 2010;1:485-491.

14 Morimoto O, Nagano H, Miyamoto A, Fujiwara Y, Kondo M, Yamamoto T, Ota H, Nakamura M, Wada H, Damdinsuren B, Marubashi S, Dono K, Umeshita K, Nakamori S, Sakon M, Monden M: Association between recurrence of hepatocellular carcinoma and alpha-fetoprotein messenger RNA levels in peripheral blood. Surg Today 2005;35:1033-1041.

15 Lemoine A, Le Bricon T, Salvucci M, Azoulay D, Pham P, Raccuia J, Bismuth H, Debuire B: Prospective evaluation of circulating hepatocytes by alpha-fetoprotein mRNA in humans during liver surgery. Ann Surg 1997; 226:43-50.

16 Witzigmann H, Geissler F, Benedix F, Thiery J, Uhlmann D, Tannapfel A, Wittekind C, Hauss J: Prospective evaluation of circulating hepatocytes by alpha-fetoprotein messenger RNA in patients with hepatocellular carcinoma. Surgery 2002;131:34-43.

17 Clinical Practice Guidelines for Hepatocellular Carcinoma - The Japan Society of Hepatology 2009 update. Hepatol Res 2010;40(suppl 1):2-144.

18 Sakon M, Nagano H, Nakamori S, Dono K, Umeshita K, Murakami T, Nakamura H, Monden M: Intrahepatic recurrences of hepatocellular carcinoma after hepatectomy: analysis based on tumor hemodynamics. Arch Surg 2002;137:94-99.

19 Jeng KS, Sheen IS, Tsai YC: Circulating messenger RNA of alpha-fetoprotein: a possible risk factor of recurrence after resection of hepatocellular carcinoma. Arch Surg 2004;139:1055-1060.

20 Cheung TT, Poon RT, Yuen WK, Chok KS, Jenkins CR, Chan SC, Fan ST, Lo CM: Long-term survival analysis of pure laparoscopic versus open hepatectomy for hepatocellular carcinoma in patients with cirrhosis: a single-center experience. Ann Surg 2013;257:506-511. 
21 Tranchart H, Di Giuro G, Lainas P, Roudie J, Agostini H, Franco D, Dagher I: Laparoscopic resection for hepatocellular carcinoma: a matched-pair comparative study. Surg Endosc 2010;24:1170-1176.

22 Lee KF, Chong CN, Wong J, Cheung YS, Wong J, Lai P: Long-term results of laparoscopic hepatectomy versus open hepatectomy for hepatocellular carcinoma: a case-matched analysis. World J Surg 2011;35:22682274.

23 Kim H, Suh KS, Lee KW, Yi NJ, Hong G, Suh SW, Yoo T, Park MS, Choi Y, Lee HW: Long-term outcome of laparoscopic versus open liver resection for hepatocellular carcinoma: a case-controlled study with propensity score matching. Surg Endosc 2014;28:950-960.

24 Truant S, Bouras AF, Hebbar M, Boleslawski E, Fromont G, Dharancy S, Leteurtre E, Zerbib P, Pruvot FR: Laparoscopic resection vs. open liver resection for peripheral hepatocellular carcinoma in patients with chronic liver disease: a case-matched study. Surg Endosc 2011;25:3668-3677.

25 Kobayashi S, Nagano H, Marubashi S, Kawamoto K, Wada H, Eguchi H, Tanemura M, Umeshita K, Doki Y, Mori M: Hepatectomy based on the tumor hemodynamics for hepatocellular carcinoma: a comparison among the hybrid and pure laparoscopic procedures and open surgery. Surg Endosc 2013;27:610-617. 